\title{
Procalcitonin as a marker of sepsis and outcome in patients with neurotrauma: an observation study
}

\author{
Shuixiang Deng ${ }^{1 \dagger}$, Hechen Zhu ${ }^{1 \dagger}$, Kunlun Wang $^{2 \dagger}$ and Tongwa Cao ${ }^{1 *}$
}

\begin{abstract}
Background: Procalcitonin (PCT) is a reliable biomarker of sepsis and infection. The level of PCT associated with sepsis and infection in patients with traumatic brain injury is currently unknown. The purpose of this study was to investigate the value of PCT and C-reactive protein (CRP) as diagnostic markers of sepsis and to evaluate the prognostic value of these markers related to the severity of injury, sepsis and mortality.

Methods: 105 adult patients with neurotrauma were enrolled in this study from June 2011 to February 2013. PCT and CRP were measured at admission and 2, 3, 5 and 7 days after admission. The sepsis criteria established by American College of Chest Physicians /Society of Critical Care Medicine Consensus Conference were used to identify patients. Injury Severity Score (ISS) and Glasgow Coma Score (GCS) were used to assess the severity of the injury. All these patients were monitored for 28 days.
\end{abstract}

Results: At admission, the median level of PCT was consistent with the severity of brain injury as follows: mild $0.08 \mathrm{ng} / \mathrm{ml}$ (0.05 - 0.13), moderate $0.25 \mathrm{ng} / \mathrm{ml}(0.11-0.55)$ and severe $0.31 \mathrm{ng} / \mathrm{ml}(0.17-0.79)$, but the range of CRP levels varied greatly within the given severity of brain injury. Seventy-one (67.6\%) patients developed sepsis. The initial levels of PCT at admission were statistically higher in patients with sepsis, compared with patients with systemic inflammatory response syndrome (SIRS), but there were no differences in the initial concentration of CRP between sepsis and SIRS. After adjusting for these parameters, multivariate logistic regression analysis revealed that $P C T$ was an independent risk factor for septic complications $(p<0.05)$. The areas under the ROCs at admission for the prediction of mortality were $0.76(p<0.05)$ and 0.733 for PCT and CRP, respectively.

Conclusions: Increased levels of PCT during the course of the ICU stay could be an important indicator for the early diagnosis of sepsis after neurotrauma. In addition, high serum levels of PCT in patients with neurotrauma at admission indicate an increased risk of septic complications, and the daily measurement of PCT assists in guiding antibiotic therapy in neurotrauma patients.

Keywords: Procalcitonin, Systemic inflammatory response syndrome (SIRS), Sepsis, Mortality, Traumatic brain injury

\section{Background}

Traumatic brain injury (TBI) accounts for a large proportion of injury-related deaths and disabilities in developed countries [1]. Patients with TBI have an increased risk of consequent infection and sepsis, which requires prompt diagnosis and treatment with appropriate antimicrobial agents to reduce associated morbidity and mortality [2-4]. Severe neurotrauma is a great potential cause of systemic inflammatory response syndrome (SIRS)

\footnotetext{
*Correspondence: caotongwa@sohu.com

${ }^{\dagger}$ Equal contributors

'Division of Intensive Care Unit, Huashan Hospital, Fudan University, 12 Wulumuqi Road (middle), Shanghai, China

Full list of author information is available at the end of the article
}

[5], and the currently available markers including fever, C-reactive protein (CRP), IL-6 and total leukocyte count lack sensitivity and specificity thereby making it difficult to distinguish SIRS from infectious diseases [6]. Reducing the risk of infection and subsequent sepsis through adherence to infection control measures is essential to lower in-hospital deaths among patients with TBI.

In the last decade, several papers have been published that report procalcitonin (PCT) as a novel biomarker that is recommended for the assessment of bacterial infection [7-11]. PCT is composed of 116 amino acids and is physiologically synthesised by thyroid $\mathrm{C}$ cells, but in the case of sepsis, there is an extrathyroidal origin of PCT

\section{Biomed Central}

(c) 2013 Deng et al.; licensee BioMed Central Ltd. This is an open access article distributed under the terms of the Creative Commons Attribution License (http://creativecommons.org/licenses/by/2.0), which permits unrestricted use, distribution, and reproduction in any medium, provided the original work is properly cited. 
genesis $[7,8]$. In normal conditions, serum PCT levels are negligible, but they become detectable at the onset of infection. PCT levels are closely related to the severity and evolution of infection, and they are thought to be associated with poor prognosis in patients with septicaemia $[12,13]$. PCT has been used to evaluate the evolution of infections and sepsis in patients with trauma and surgical conditions $[5,14,15]$. The changes of PCT level in response to therapeutic treatment have also been reported, which suggests prognostic significance in a variety of clinical settings [16,17]. The persistent increase of PCT level is associated with an increased length of ICU stay and mortality [18]. PCT-guided strategies have significantly reduced the use of antibiotics [19]. Among the proposed biomarkers of sepsis, PCT appears to be the most promising in terms of its diagnostic and prognostic benefits. Recently, a newly developed PCT assay with significantly higher discriminatory power has been put into practice [20]. There is a lack of substantial data regarding the use of PCT in the treatment of traumatic brain injury [5,21].

The aim of this study was to investigate the levels of PCT and CRP that are used as diagnostic markers of sepsis in patients with traumatic brain injury at the time of hospital admission, and to evaluate the prognostic value of these markers related to the severity of injury, sepsis and mortality.

\section{Methods}

\section{Patients and methods}

After approval by the Ethics Committee of Huashan Hospital, Fudan University, Shanghai, China (approval number: 2011-281), informed consent was obtained from each patient or their representatives. A total of 105 patients with isolated traumatic brain injury who were admitted to the ICU of our tertiary university teaching hospital from June 2011 to February 2013 were enrolled in this prospective observational study. Patients were included if they fulfilled the following criteria: age over 18 years old and admission within 24 hours of injury. Patients with pre-existing febrile illness, suffering from burns, an Abbreviated Injury Scale (AIS) for all other body regions injury $\geq 3$, patients under immune suppressive therapy, patients already on antibiotics for $\geq 3$ days before admission, and patients who did not survive for 48 hours after admission were excluded from the study.

\section{Clinical data collection}

All patients in the ICU were monitored by ECG and arterial pressure monitoring as a part of routine clinic practice. The clinical care of the patients was guided by the criteria established by the Brain Trauma Foundation and the American Association of Neurological Surgeons [22-24].

Endotracheal intubation was carried out, and mechanical ventilation was initiated as clinically required. Glasgow
Coma Score (GCS) and Injury Severity Score (ISS) were used to define the injury severity $[25,26]$. GCS and ISS were calculated within the first 24 hours after admission and were repeated every day thereafter. The levels of PCT and CRP were measured on days 1 (admission day), 2, 3, 5 and 7. All data including clinical signs, laboratory observations, microbiological pathogens, medicine options, complications, 28-day survival rate and duration treatment and length of stay in ICU as well as the data necessary to evaluate the ISS were documented.

\section{Definitions}

The main complication was systemic inflammation, and the various stages of sepsis were defined according to the criteria established by the American College of Chest Physicians/the Society of Critical Care Medicine [6]. We evaluated the onset of sepsis during the first observation week. Patients were allocated to four groups post hoc: (1) NoSIRS (neither SIRS nor sepsis) (2) SIRS (3) sepsis and (4) severe sepsis group (including severe sepsis and septic shock).The stratification of trauma severity in terms of the GCS score was generally recognised and accepted by professionals [25]. Then, patients were allocated to three groups post hoc: (1) GCS13-15 group (2) GCS9-12 group and (3) GCS3-8 group. The patients who survived longer than 28 days were considered as survivors.

\section{Measurement of plasma PCT and CRP}

According to the manufacturer's instructions, PCT level was measured by an electrochemiluminescence immunoassay (ECLIA) B.R.A.H.M.S. PCT ELECSYS ${ }^{\circ}$ using an automated Roche Elecsys and Cobase immunoassay analyser [20]. This new assay is more sensitive compared with the conventional assays, and the sensitivity of this assay is $0.02 \mathrm{ng} / \mathrm{ml}$. CRP level was determined using a fully automated IMMAGE Immunochemistry System (Beckman Coulter, USA), which was derived from the highly sensitive near infrared particle immunoassay method. The lower limit of detection is $3.45 \mathrm{mg} / \mathrm{L}$.

\section{Statistical analysis}

Normally distributed variables are presented as the mean $+/$ - standard deviation (SD), and nonparametric continuous variables are expressed as the median and inter-quartile ranges (IQR). PCT levels among sepsis groups or GCS groups were carried out using Kruskal-Wallis tests (data not normally distributed), if statistical significance of differences was detected, then the Mann-Whitney U-test (nonparametric analysis) was used for further comparisons between the two sepsis groups or GCS groups. We used the Pearson chi-square test $\left(\chi^{2}\right.$ test) or Fisher's exact test to compare proportions. Multivariate logistic regression was used to assess the performance of the variables in the prediction of sepsis. 
Based on the results of univariate analysis, we selected three confounding variables (age $(\mathrm{p}=0.789)$, sex $(\mathrm{p}=0.779)$, ISS $(\mathrm{p}<0.05))$ that required adjustment to minimise their influence on the results. Receiver operating characteristic curves (ROC) and the area under the curve (AUC) were employed to assess the predictive performance of the models. A two-tailed $\mathrm{p}$ value $<0.05$ was considered to be statistically significant. Statistical evaluation of data was analysed using the SPSS version 17.0 software.

\section{Results}

\section{Demographics and clinical characteristics of patients}

One hundred five isolated traumatic brain injury patients without underlying illness or long-term medication were admitted within 24 hours after accident. Among these patients, $90(85.7 \%)$ were traumatised by motor vehicle, whereas 15 casualties were suffered from trauma following a fall from a greater height. The mean age of the patients was 56 years and ranged from 18 to 80 years with 79 males and 26 females. The demographics and clinical characteristics of patients are presented in Table 1.

\section{Generation of PCT and CRP after trauma}

The median levels of serum PCT and CRP in the overall patient cohort were $0.2 \mathrm{ng} / \mathrm{ml}$ and $23.1 \mathrm{mg} / \mathrm{L}$, respectively. After comparisons were carried out among the different groups that were divided according to their GCS scores, an incremental increase in the median level of PCT that was consistent with increasing severity of brain injury was observed. The median level of PCT in patients with mild brain injury was significantly lower than that in patients with moderate and severe brain injury. The dynamic changes of PCT and CRP levels after neurotrauma are depicted in Figure 1.

\section{Development of sepsis}

The incidence of SIRS or sepsis occurred in 79\% patients with traumatic brain injury. Among 105 patients, 71 (67.6\%) were clinically diagnosed as septic including 15 patients (14.3\%) who suffered from severe sepsis or septic shock. Positive blood culture was detected in 43 pneumonia patients, 10 peritonitis patients, 9 urinary tract infection patients, 7 wound infection patients and 8 patients with infection of other parts of body. Sepsis, severe sepsis or septic shock was frequently and directly diagnosed during the observation period in patients with initially high levels of serum PCT. On the contrary, the initial level of CRP was not associated with these categories of infection as shown in Figure 2 and Table 2. For example, the patients PCT level with $0.05 \mathrm{ng} / \mathrm{ml}$ that ranged from $<0.03$ to $0.098 \mathrm{ng} / \mathrm{ml}$ initial median (quartiles) did not develop SIRS or sepsis during the entire course of observation. Conversely, the patients with $0.105 \mathrm{ng} / \mathrm{ml}$ that ranged from 0.085 to $0.328 \mathrm{ng} / \mathrm{ml}$ initial median PCT level developed SIRS $(\mathrm{p}=0.002)$, and those with $0.27 \mathrm{ng} / \mathrm{ml}$ that ranged from 0.12 to $0.61 \mathrm{ng} / \mathrm{ml}$ initial median PCT level developed sepsis $(\mathrm{p}=0.001)$. The patients with $0.57 \mathrm{ng} / \mathrm{ml}$ that ranged from 0.23 to $1.45 \mathrm{ng} / \mathrm{ml}$ initial median PCT level developed septic shock $(\mathrm{p}<0.001)$. There was a significant difference in the initial level of PCT between SIRS and sepsis $(\mathrm{p}=0.046)$. PCT concentration remained elevated in patients with sepsis, severe sepsis or septic shock, but it rapidly fell to a near-normal value in the patients who did not develop sepsis (Figure 3). There was a significant difference in the median level of PCT between the measurements at admission and 7 days after admission (0.32 vs $0.2 \mathrm{ng} / \mathrm{ml}, \mathrm{p}<0.002)$. Univariate logistic regression analysis indicated that the initial white blood cell count (WBC), CRP and PCT were the high risk factors for sepsis/severe sepsis or septic shock, and after adjusting for these parameters, multivariate logistic regression analysis indicated that the odds ratio for the development of sepsis/severe sepsis or septic shock increased if PCT was $>0.215 \mathrm{ng} / \mathrm{ml}$, but other markers had no statistical significance (Table 3).

\section{Serum PCT and prognosis}

Of the 105 patients, 16 died of severe head trauma with a GCS score of 3-8 within 28 days after trauma, which accounted for $15.24 \%$ mortality. The initial PCT and CRP levels after trauma were significantly higher in nonsurvivors than those in survivors $(\mathrm{p}<0.05$ by

Table 1 Demographic data of series of patients by GCS subgroup

\begin{tabular}{|c|c|c|c|c|c|}
\hline Parameters & GCS13-15Group & GCS9-12Group & GCS3-8Group & Totality & $p$ value \\
\hline Number (n) & 33 & 38 & 34 & 105 & - \\
\hline Age $($ mean $\pm S D)$ & $55 \pm 14$ & $56 \pm 14$ & $55 \pm 14$ & $55 \pm 13$ & 1.0 \\
\hline Gender (male/female) & $21 / 12$ & $31 / 7$ & $27 / 7$ & $79 / 26$ & 0.172 \\
\hline ICU stay(d) & $12.4 \pm 5.5$ & $15.2 \pm 9.6$ & $16 \pm 7.1$ & $14.6 \pm 7.7$ & 0.125 \\
\hline Initial ISS & $4 \pm 3$ & $13 \pm 5$ & $17 \pm 5$ & $12 \pm 7$ & 0.001 \\
\hline Initial C-reactive protein (0-24 hours) (median, quartiles) (mg/l) & $10.23(3.5,15.9)$ & $23.75(13.3,42.5)$ & $44.85(22.4,78.1)$ & $23.1(10.3,46.1)$ & 0.244 \\
\hline Initial procalcitonin (0-24 hours)(median, quartiles) (ng/ml) & $0.08(0.05,0.13)$ & $0.25(0.11,0.55)$ & $0.31(0.17,0.79)$ & $0.2(0.08,0.5)$ & 0.110 \\
\hline Mortality (\%) & 1.0 & 2.9 & 11.3 & 15.2 & 0.000 \\
\hline
\end{tabular}




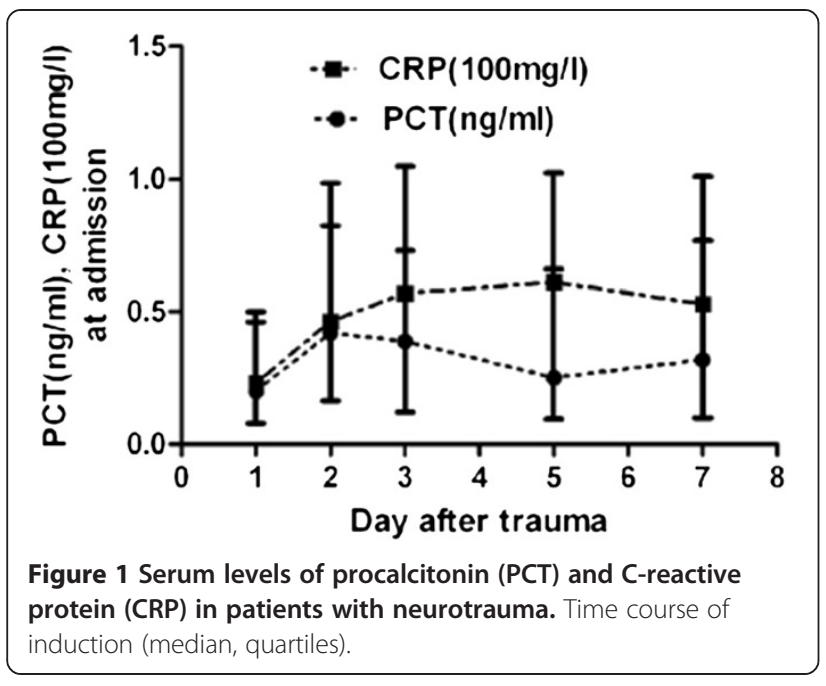

Mann-Whitney U-test). However, serum PCT was superior compared to CRP in the prediction of mortality with a greater area under the ROC curve (0.76 vs 0.733 ).

\section{Discussion}

TBI patients present a particular challenge in the diagnosis of sepsis complications as the trauma per se predisposes patients to provoking a systemic inflammatory response that often masks the initial clinical symptoms of sepsis. Therefore, patients with TBI are considered to be at a high risk for sepsis complications, which complicate the ability to distinguish sepsis from SIRS in a clinical setting by using ordinary clinical signs and symptoms such as WBC, high fever and mal-perspiration. Alternatively,

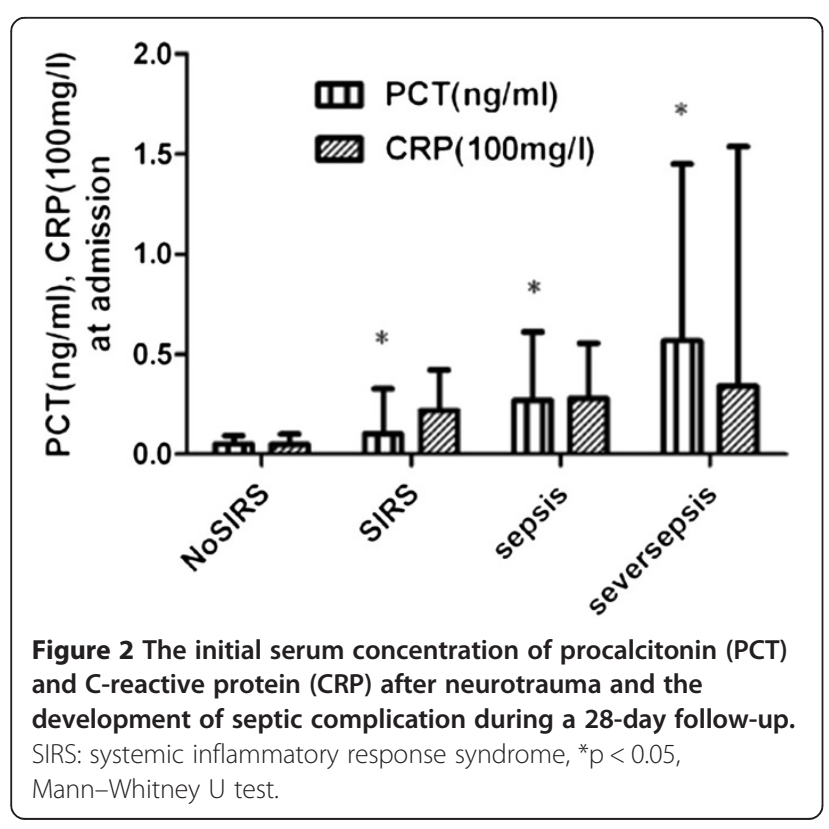

PCT is considered as an acute-phase biomarker of the systemic inflammatory response [27]. We carried out this study to determine whether PCT and CRP can be diagnostic markers of sepsis or prognostic indicators of mortality of neurotrauma patients.

In the present study, PCT level increased in the first 24 hours after trauma in patients with $\mathrm{GCS}<12$. However, the median PCT level in patients with GCS 9-12 was lower than that of the patients with GCS $<8$. Various levels of PCT and CRP were detected in patients with TBI. Both biomarkers showed that the variation of CRP levels at different intervals after trauma was a uniform response without significant association with trauma severity. The development of various stages of sepsis was also observed. Furthermore, the concentration of CRP remained elevated for several days after trauma. The variation of PCT levels was moderately consistent with the severity of the trauma that was previously reported by several authors $[5,28,29]$. Of particular note, the initial median level of PCT was closely associated with the severity of TBI. The mechanism of this phenomenon could be explained by the observation that SIRS is a more common occurrence that is promptly activated in neurotrauma patients or that the PCT level is assayed by a sophisticated instrument, therefore, this phenomenon diminished the value of PCT being used as a specific marker of sepsis in these patients.

As noted, the median PCT, but not CRP, level was determined to be significantly higher in patients with sepsis, severe sepsis or septic shock compared to the levels in patients with SIRS after the evaluation of patients according to criteria established by the ACCM/SCCM. CRP is another acute inflammatory protein and it often takes a long time to activate a reaction whereby its levels are elevated in response to inflammation. Studies have shown that the kinetics of CRP in multiple-trauma is slower and sustains longer than PCT [30]. These findings could be due mainly to the low sensitivity of CRP that is responsive to trauma at an early stage. According to the multivariate logistic regression analysis, after adjustment for age and gender, the PCT value was an independent risk factor of sepsis. Patients with high initial PCT levels were subjected to a 290 -fold risk of sepsis compared to those with a low initial PCT level.

There are several studies that have reported using PCT to guide antibiotic therapy in different settings [31-33]. Experts have reached a consensus and developed guidelines for the clinical interpretation of elevated PCT and the risk stratification according to different elevated PCT levels. In particular, the negative predictive value $(\mathrm{PCT}<0.1 \mathrm{ng} / \mathrm{ml})$ to exclude a risk of sepsis is used. In the present study, we conventionally administered a single shot antibiotic to neurotrauma patients 
Table 2 The original data of PCT and CRP in patients of sepsis subgroup

\begin{tabular}{|c|c|c|c|c|c|c|}
\hline \multirow[t]{2}{*}{ Group } & \multicolumn{2}{|c|}{ PCT (ng/ml)(d1) } & \multicolumn{2}{|c|}{ CRP (mg/L)(d1) } & \multicolumn{2}{|c|}{ PCT (ng/ml)(d2) } \\
\hline & Median & IQR & Median & IQR & Median & IQR \\
\hline No SIRS & 0.093 & $(0.050,0.093)$ & 4.86 & $(3.22,10.30)$ & 0.120 & $(0.080,0.300)$ \\
\hline SIRS & 0.105 & $(0.085,0.328)$ & 21.90 & $(14.48,42.22)$ & 0.295 & $(0.148,0.575)$ \\
\hline Sepsis & 0.270 & $(0.120,0.610)$ & 27.85 & $(15.12,55.50)$ & 0.555 & $(0.233,0.857)$ \\
\hline Severe sepsis & 0.570 & $(0.230,1.450)$ & 34.30 & $(22.40,154.0)$ & 1.300 & $(0.360,2.600)$ \\
\hline
\end{tabular}

on admission to prevent infection. We determined that the odds ratio for the development of sepsis was increased as PCT $>0.215 \mathrm{ng} / \mathrm{ml}$, and according to the daily measurement of the PCT value, if PCT remains lower than $0.1 \mathrm{ng} / \mathrm{ml}$, further antibiotic treatment was not required due to the low risk for sepsis. This finding was consistent with Marc and colleagues [33]. We also determined that PCT concentration rapidly decreased to a near-normal value in patients who did not develop sepsis, thus, during the further course of treatment, if the PCT level remained $<0.1 \mathrm{ng} / \mathrm{ml}$ and the combined clinical symptoms did not provided any evidence for sepsis, no antibiotics were required. Thus, the daily use of the negative predictive value of PCT would be clinically helpful.

Our study has several important implications for clinicians. Although the present study population is too small to infer the importance of serum PCT in neurotrauma patients, it definitively indicates that serum PCT could be involved in the entire course of infections to facilitate the management of sepsis in critical care. With the newest assay method, serum PCT is detected with a high accuracy that other currently available tests cannot provide. The accuracy of the serum PCT reference range is not perfect, but it could guide physicians

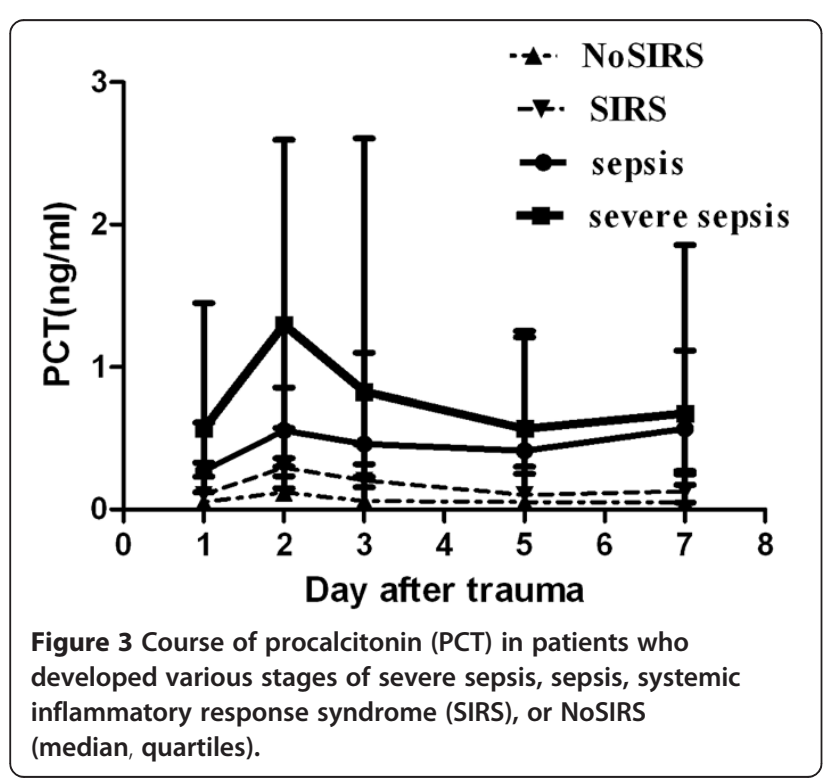

in developing a clinical strategy and incrementally managing neurotrauma patients with sepsis. Additionally, the daily measurement of PCT aids physicians in guiding antibiotic therapy in neurotrauma patients. The test can be performed within 30 minutes and provides valuable information long before culture results are available.

There are some limitations to the present study. First, the sample size of the study was relatively small, and consequently, the power to demonstrate the interaction among serum PCT and prognosis was limited. Second, most patients were young males, which did not represent the entire demographics of neurotrauma patients. Third, the present study did not analyse the kinetics of PCT level and its association with other inflammatory cytokines levels in these patients. Finally, the pathophysiology of neurotrauma was complex and was influenced by patient-specific factors (age, sex) and injury-specific factors (mechanism, severity). Thus, one single biomarker will not be able to accurately predict the clinical course of neurotrauma patients.

\section{Conclusions}

These data substantiate the hypothesis that increased levels of PCT during the period of hospitalisation could be an important indicator for the early recognition of bacterial infection and sepsis as well as provide early information about the presence of complications after TBI. These data also indicate that the daily measurement of PCT would be clinically useful. The authenticity and soundness of the findings obtained from our study need to be evaluated in a future study.

Table 3 Multivariate logistic regression analysis of the risk factors of sepsis

\begin{tabular}{lccccc}
\hline & B & S.E. & Wald & $\mathbf{p}$ & odds ratio \\
\hline Initial WBC & 0.062 & 0.077 & 0.661 & 0.416 & 1.064 \\
Sex & 0.580 & 0.836 & 0.481 & 0.488 & 1.787 \\
Age & 0.010 & 0.027 & 0.148 & 0.700 & 1.010 \\
initial ISS & 0.352 & 0.084 & 17.694 & 0.000 & 1.422 \\
Initial CRP & 0.016 & 0.013 & 1.600 & 0.206 & 0.984 \\
Initial PCT & 5.672 & 2.399 & 5.589 & 0.018 & 290.681 \\
\hline
\end{tabular}




\section{Competing interests}

The authors declare that they have no competing interest.

\section{Authors' contributions}

TC developed the study design and coordinated its implementation. SD participated in data collection and interpretation/discussion of results and drafted and revised the manuscript. $\mathrm{HZ}$ participated in guiding the study design and revised the manuscript. KW was responsible for patient recruitment as well as data collection and carried out the statistical analysis. All authors read and approved the final manuscript.

\section{Acknowledgments}

We would like to thank the medical staff of the Department of Intensive Care Unit for their participation in the study. The PCT detection agent was kindly donated by BRAHMS Diagnostics, Germany.

\section{Author details}

${ }^{1}$ Division of Intensive Care Unit, Huashan Hospital, Fudan University, 12 Wulumuqi Road (middle), Shanghai, China. ${ }^{2}$ Department of emergency, Jinshan Hospital, Fudan University, Longhang Road, Shanghai, China.

Received: 10 July 2013 Accepted: 1 November 2013

Published: 15 December 2013

\section{References}

1. Rutland-Brown W, Langlois JA, Thomas KE, Xi YL: Incidence of traumatic brain injury in the United States, 2003. J Head Trauma Rehabil 2006, 21:544-548.

2. Selassie AW, Fakhry SM, Ford DW: Population-based study of the risk of in-hospital death after traumatic brain injury: the role of sepsis. J Trauma 2011, 71:1226-1234.

3. Kourbeti IS, Papadakis JA, Neophytou C, Filippou M, Loannou A, Karabetsos DA, Bertsias G, Anastasaki M, Vakis AF: Infections in patients with traumatic brain injury who undergo neurosurgery. Br J Neurosurg 2011, 25:9-15.

4. Kourbeti IS, Vakis AF, Papadakis JA, Karabetsos DA, Bertsias G, Filippou M loannou A, Neophytou C, Anastasaki M, Samonis G: Infections in traumatic brain injury patients. Clin Microbiol Infect 2012, 18:359-364.

5. Oconnor E, Venkatesh B, Mashongonyika C, Lipman J, Hall J, Thomas P: Serum procalcitonin and C-reactive protein as markers of sepsis and outcome in patients with neurotrauma and subarachnoid haemorrhage. Anaesth Intensive Care 2004, 32:465-470.

6. Levy MM, Fink MP, Marshall JC, Abraham E, Angus D, Cook D, Cohen J, Opal SM, Vincent JL, Ramsay G: SCCM/ESICM/ACCP/ATS/SIS International Sepsis Definitions Conference. Crit Care Med 2001, 2003(31):1250-1256.

7. Irwin AD, Carro ED: Procalcitonin. Arch Dis Child Educ Pract Ed 2011, 96:228-233.

8. Didebulidze K, Manjavidze N, Ubiria I, Gogberashvili K: Procalcitonin - marker of severe infection and sepsis. Georgian Med News 2007, 153:22-27.

9. Riedel S, Melendez JH, An AT, Rosenbaum JE, Zenilman JM: Procalcitonin as a marker for the detection of bacteremia and sepsis in the emergency department. Am J Clin Pathol 2011, 135:182-189.

10. Reinhart K, Meisner M: Biomarkers in the critically ill patient: procalcitonin. Crit Care Clin 2011, 27:253-263.

11. Sudhir U, Venkatachalaiah RK, Kumar TA, Rao MY, Kempegowda P: Significance of serum procalcitonin in sepsis. Indian J Crit Care Med 2011, 15:1-5.

12. Schneider $H G$, Lam QT: Procalcitonin for the clinical laboratory: a review. Pathology 2007, 39:383-390.

13. Karlsson S, Heikkinen M, Pettila V, Alila S, Vaisanen S, Pulkki K, Kolho E, Ruokonen E: Predictive value of procalcitonin decrease in patients with severe sepsis: a prospective observational study. Crit Care 2010, 14:R205.

14. Balci C, Sivaci R, Akbulut G, Karabekir HS: Procalcitonin levels as an early marker in patients with multiple trauma under intensive care. $J$ Int Med Res 2009, 37:1709-1717.

15. Castelli GP, Pognani C, Cita M, Paladini R: Procalcitonin as a prognostic and diagnostic tool for septic complications after major trauma. Crit Care Med 2009, 37:1845-1849.

16. Georgopoulou AP, Savva A, Giamarellos-Bourboulis EJ, Georgitsi M, Raftogiannis M: Early changes of procalcitonin may advise about prognosis and appropriateness of antimicrobial therapy in sepsis. J Crit Care 2011, 26:331.
17. Haasper C, Kalmbach M, Dikos GD, Meller R, Muller C, Krettek C, Hildebrand F, Frink M: Prognostic value of procalcitonin (PCT) and/or interleukin-6 (IL-6) plasma levels after multiple trauma for the development of multi organ dysfunction syndrome (MODS) or sepsis. Technol Health Care 2010, 18:89-100.

18. Seligman R, Meisner M, Lisboa TC, Hertz FT, Filippin TB, Fachel JM, Teixeira PJ: Decreases in procalcitonin and C-reactive protein are strong predictors of survival in ventilator-associated pneumonia. Crit Care 2006, 10:R125.

19. Heyland DK, Johnson AP, Reynolds SC, Muscedere J: Procalcitonin for reduced antibiotic exposure in the critical care setting: A systematic review and an economic evaluation. Crit Care Med 2011, 39:1792-1799.

20. De Wolf HK, Gunnewiek JK, Berk Y, van den Quweland J, De Metz M: Comparison of a new procalcitonin assay from roche with the established method on the brahms kryptor. Clin Chem 2009, 55:1043-1044.

21. Sauerland S, Hensler T, Bouillon B, Rixen D, Raum MR, Andermahr J, Neugebauer EA: Plasma level of procalcitonin and neopterin in multiple trauma patients with or without brain injury. J Neurotrauma 2003, 20:953-960.

22. Brain Trauma Foundation: American Association of Neurological Surgeons: Congress of Neurological Surgeons: Guidelines for the management of severe traumatic brain injury. J Neurotrauma 2007, 24(Suppl 1):S1-S106

23. Maas Al, Dearden M, Servadei F, Stocchetti N, Unterberg A: Current recommendations for neurotrauma. Curr Opin Crit Care 2000, 6:281-292.

24. Bratton SL, Chestnut RM, Ghajar J, McConnell, Hammond FF, Harris OA, Hartl R, Manley GT, Nemecek A, Newell DW: Guidelines for the management of severe traumatic brain injury. I. Blood pressure and oxygenation. J Neurotrauma 2007, 24(Suppl 1):S7-S13.

25. Teasdale $G$, Jennett B: Assessment of coma and impaired consciousness. A practical scale. Lancet 1974, 2:81-84.

26. Civil ID, Schwab CW: The Abbreviated Injury Scale, Revision: A Condensed Chart for clinical use. J Trauma 1985, 1988(28):87-90.

27. Nijsten MW, Olinga P, The TH, De Vries EG, Koops HS, Groothuis GM, Limburg PC, Ten, Duis HJ, Moshage H, Hoekstra HJ, Bijzet J, Zwaveling JH: Procalcitonin behaves as a fast responding acute phase protein in vivo and in vitro. Crit Care Med 2000, 28:458-461.

28. Wanner GA, Keel M, Steckholzer U, Beier W, Stocker R, Ertel W: Relationship between procalcitonin plasma levels and severity of injury, sepsis, organ failure, and mortality in injured patients. Crit Care Med 2000, 28:950-957.

29. Maier M, Wutzler S, Lehnert M, Szermutzky M, Wyen H, Bingold T, Henrich D, Walcher F, Marzi l: Serum procalcitonin levels in patients with multiple injuries including visceral trauma. J Trauma 2009, 66:243-249.

30. Meisner M, Adina H, Schmidt J: Correlation of procalcitonin and C-reactive protein to imflammation, complications, and outcome during the intensive care unit course of multiple-trauma patients. Crit Care 2006, 10:R1.

31. Christ-Crain M, Jaccard-Stolz D, Bingisser R, Gencay MM, Huber PR, Tamm M, Müller B: Effect of procalciton-guided treatment on antibiotic use and outcome in lower respiratory tract infections: cluster-randomized, single-blinded intervention trail. Lancet 2004, 363(9409):600-607.

32. Christ-Crain M, Stolz D, Bingisser R, Müller C, Miedinger D, Huber PR, Zimmerli W, Harbarth S, Tamm M, Müller B: Procalciton-guidance of antibiotic therapy in community-acquired pneumonia: a randomized trial. Am J Respir Crit Care Med 2006, 174(1):84-93.

33. Marc E, Menager C, Moulin F, Stos B, Chalumeau M, Guerin S, Lebon P, Brunet F, Raymond J, Gendrel D: Procalcitonin and viral meningitis: reduction of unnecessary antibiotics by measurement during an outbreak. Arch Pediatr 2002, 9(4):358-364.

\section{doi:10.1186/1471-2253-13-48}

Cite this article as: Deng et al:: Procalcitonin as a marker of sepsis and outcome in patients with neurotrauma: an observation study. BMC Anesthesiology 2013 13:48. 